\title{
Republic of Madagascar: Poverty Reduction Strategy Paper Annual Progress Report- Joint Staff Advisory Note
}

The attached Joint Staff Advisory Note (JSAN) of the Poverty Reduction Strategy Paper Annual Progress Report for the Republic of Madagascar, prepared jointly by the staffs of the World Bank and the IMF, was distributed with the member country's Poverty Reduction Strategy Paper Annual Progress Report to the Executive Boards of the two institutions. The objective of the JSAN is to provide focused, frank, and constructive feedback to the country on progress in implementing its Poverty Reduction Strategy (PRS).

To assist the IMF in evaluating the publication policy, reader comments are invited and may be sent by e-mail to publicationpolicy@imf.org.

Copies of this report are available to the public from

International Monetary Fund • Publication Services

$70019^{\text {th }}$ Street, N.W. • Washington, D.C. 20431

Telephone: (202) 623-7430 • Telefax: (202) 623-7201

E-mail: publications@imf.org • Internet: http://www.imf.org

\section{International Monetary Fund Washington, D.C.}





\title{
THE INTERNATIONAL DEVELOPMENT ASSOCIATION AND THE INTERNATIONAL MONETARY FUND
}

\section{REPUBLIC OF MADAGASCAR}

\author{
Poverty Reduction Strategy Paper-Annual Progress Report \\ Joint Staff Advisory Note \\ Prepared by the Staffs of the International Development Association and \\ the International Monetary Fund \\ Approved by Gobind Nankani (IDA) \\ and Thomas Krueger and Anthony Boote (IMF)
}

July 5, 2006

\section{OVERVIEW}

1. The government of Madagascar prepared its first Poverty Reduction Strategy Paper (PRSP) in July 2003' ${ }^{1}$, updated it in mid-2005 and finalized its 2005 Annual Progress Report (APR) for the calendar year 2005 in June 2006. The PRSP was updated to incorporate the longer term vision (to 2015), Madagascar Naturellement, which foresees a transition from a subsistence economy to a market economy to realize Madagascar's potential through optimal use of its resources, while respecting the environment. The vision puts an enhanced emphasis on rural areas through improved productivity, increased value added, improved infrastructure, technology and partnerships. The PRSP update also incorporates the creation of the 22 regions. The PRSP update and 2005 APR provide a comprehensive overview of the results achieved, an analysis of the results, lessons learnt and challenges faced in implementing the poverty reduction strategy.

\section{This APR has addressed several of the weaknesses identified in the previous} Joint Staff Advisory Note (JSAN). First, the APR assesses the results achieved and the key

\footnotetext{
${ }^{1}$ The PRSP and its accompanying JSA was presented to the Boards of the IMF and WB in November 2003. The First Annual Progress Report, covering the first year of implementation (July 2003-June 2004) and its JSA was presented to the Boards in October 2004. The Government started producing its APR on a calendar year basis for improved alignment with its fiscal year, the first of which was produced in June 2005 for calendar year 2004 along with the PRSP update. This JSAN comments on the 2005 calendar year APR.
} 
policy measures and reforms under the three strategic axes of good governance, broad-based growth, and human development. Second, presentationally it integrates and reports on the overall government agenda, including progress on the Politique Générale de L'Etat, the annual results framework, and the original PRSP indicators. Third, it notes that the government has made progress in costing key elements of its strategy (especially, in education, health and rural water) and is continuing to improve this element as part of the preparation of the new growth and poverty reduction strategy.

3. The government is currently preparing its new growth and poverty reduction strategy, called the Madagascar Action Plan (MAP) to cover the period 2007-2011. The MAP builds on the first PRSP and is underpinned by a broad consultative process. It is being fully integrated and aligned with the national processes, and is expected to be finalized by late October 2006 and sent to Parliament with the 2007 Finance Law. This JSAN highlights areas that in the staffs views are important for the MAP and its implementation.

\section{Implementation of the Poverty Reduction Strategy}

\section{A. Poverty Reduction}

4. The APR presents a comprehensive poverty profile based on the 2005 household survey, and shows that the incidence of overall poverty is 68.7 percent, slightly lower than the level of 2001 (69.7 percent) and a significant decline from the high levels during the 2002 crisis. The poverty analysis, based on the 2005 household survey (Enquete Prioritaire auprès des Ménages, EPM), presents the trends and determinants of poverty based on a sample that is representative at the regional level. The decline in poverty was greater in rural areas than in urban areas. Rural poverty incidence was lower in 2005 (73.5 percent) than in 2001 (77.2 percent), while urban poverty incidence was higher in 2005 (52 percent) than in 2001 (43.9 percent). These trends were even more marked for the indicator measuring the depth of poverty, showing that growth during this period helped those at the bottom of the distribution, and this is mirrored in the observed reduction in inequality. As noted in the report, this is consistent with the nature of the economic shocks in 2004/5 (higher rice prices and oil prices which hurt urban consumers, while the higher producer prices for rice benefited rural producers), and the expansion of road access. Regional poverty rates show a large variation, from lows in Analamanga (44 percent) to Antananarivo (58 percent) to highs of over 80 percent in other regions. Staffs also note the progress in the human development indicators. These results are also confirmed by the perceptions of the evolution of living standards and the implementation of the PRSP. Moving forward, the availability of data on living conditions at the regional level will help inform the poverty strategy. 


\section{B. Macroeconomic Policies}

5. The APR candidly indicates that the macroeconomic objectives for 2005 , notably pertaining to growth and revenue objectives, could not be achieved. Economic growth slowed down on account of power outages and the impact of the increases in world oil prices and in electricity tariffs. End-period inflation declined, reflecting the stability in the price of the staple food (rice) and in the exchange rate, induced by a tight monetary policy. Revenue performance continued to disappoint, but a somewhat tighter expenditure policy resulted in a slight decline in the overall deficit. Exports dropped sharply on account of the end of the preferential market access to industrial country textile markets and adverse terms of trade shocks. As indicated in the most recent Joint Staff Assessment (JSA) of October 2004, greater emphasis should be placed on sound macroeconomic policies and broad-based structural reforms that would help improve the business environment, accelerate sustainable growth, diversify the economy to protect against shocks, and improve competitiveness. Efforts need to be undertaken to address the low level of fiscal revenue and persistent weaknesses in public financial management, which threaten fiscal stability.

\section{Staffs note that the medium-term fiscal framework aims to promote fiscal} consolidation while aligning expenditure with the country's PRSP objectives. Despite shortfalls in revenue and budgetary assistance during the first half of the year, the 2006 budget calls for an overall deficit on a cash basis equivalent to 10.8 percent of GDP, to be achieved through a concerted effort aimed at revenue mobilization combining tax policy and administrative measures and curtailment of domestically-financed spending mainly in nonpriority sectors. For the medium term (2005-2008), total revenues should grow by 1.5 percent of GDP owing to the termination of ad hoc tax and duty exemptions and tax administration reforms. Domestically-financed expenditures are expected to increase by 0.5 percentage point of GDP during the same period, resulting in an improvement of the domestic fiscal balance by about one percent of GDP. The overall fiscal deficit (on a cash basis, excluding grants) is expected to decline gradually to 8.5 percent in 2008 , which is broadly consistent with the authorities' inflation and debt sustainability objectives. The deficit is expected to be financed principally by foreign grants and loans mainly on IDA-equivalent terms.

\section{Looking forward, the preparation of the MAP will provide a useful opportunity} to revisit and improve the country's poverty reduction strategy in light of recent developments and experience. In particular, the authorities need to: (i) define the policies and needed supply response to achieve these goals, notably pro-poor rural, tourism and infrastructure strategies; (ii) develop medium-term macroeconomic policies underlying the attainment of the objectives; (iii) prepare the costing and prioritization of the objectives given the uncertainties faced by the Madagascar economy; and (iv) specify programs aimed at eliminating identified obstacles to growth. Also, the additional fiscal space provided by the substantial debt relief accorded to Madagascar by the Fund, the World Bank, and the African 
Development Bank under the Multilateral Debt Relief Initiative (MDRI) should be reflected in the MAP.

8. Staffs note that, despite recent years' favorable growth performance, the foundations for future growth remain fragile: (i) growth has been narrowly based on the garment and shellfish sectors, which employ only a small fraction of the labor force; (ii) the industrial base needs to be broadened; (iii) agricultural output, which accounts for about 26 percent of GDP, has expanded only at a slow pace; (iv) the economy remains highly vulnerable to exogenous shocks; and (v) the private sector is not competitive because of an opaque business environment and administrative interventions that raise costs without adding value. In addition, the termination of the Agreement on Textiles and Clothing and the scheduled end of the U.S. African Growth and Opportunity Act (AGOA) III in 2007 poses a risk to Madagascar's growth prospects. This risk can be managed if the government takes decisive actions to improve the investment climate.

\section{Governance and Public Sector Management}

9. Staffs welcome the sustained efforts to improve public financial management, as outlined in the APR, which continue to be guided by the government's annual Priority Action Plan (PAP). To consolidate and deepen the reform agenda outlined in the APR, the key priorities for the next 12 months include: (i) progress in domestic revenue mobilization; (ii) strengthening of internal control mechanisms, in particular with regard to expenditure commitments; (iii) simplifying the expenditure management framework, (iv) further strengthening of capacity to prepare and execute the budget in priority ministries (e.g. education, health, infrastructure); and (v) implementing the new Procurement Code, with adequate training for sector ministry procurement staff.

10. Reasonable progress on the public sector governance agenda was triggered by substantial investments in training and capacity building, in particular in the areas of public financial management, planning, change management and monitoring and evaluation. The Program of Reform for improving the efficiency of the administration (PREA) is operational. As part of its national decentralization strategy, the government is setting up a Local Development Fund with the objective of improving service delivery at the local level. Moving forward, it will be important to make operational the new financing framework for local governments and to clarify the fiscal rules governing decentralization.

11. Progress in the fight against corruption has been mixed. The $2004 \mathrm{WBI}$ governance indicators continue to confirm that Madagascar is well above Sub-Saharan African average in all examined areas and in particular in the control of corruption, regulatory quality as well as voice and accountability. At the same time, progress is slower than expected as confirmed by the Transparency International Corruption Perception Index of 2005: Madagascar was ranked 97th out of 158 countries (its previous rankings were no. 
82 out of 145 in 2004, no. 88 out of 133 in 2003 and no. 98 out of 102 in 2002). The staffs support the government's intention to focus on addressing fraud and corruption in certain key sectors (e.g. mining, forestry, judiciary) and on further strengthening the regular and institutional framework for the fight against corruption.

\section{Structural Policies for Growth and Investment}

\section{As noted above, growth remains central to the achievement of the ambitious}

MAP goals. The APR rightly discusses the key growth sectors, including mining and mineral exploitation, fishing, tourism, manufacturing, and the Export Processing Zone (EPZ) enterprises. It does not, however, discuss the benefits of trade liberalization to growth nor the recent measures undertaken by the authorities to streamline and simplify the tariff regime. Among future planned initiatives, the priorities include: setting up the Economic Development Board for Madagascar; elaboration of a new investment code; developing the growth pole initiative; and undertaking analytical work to identify the binding constraints to growth. Priority should also be placed on assessing the benefits of further trade liberalization. The government has recognized the importance of increasing the quantity and quality of physical and human capital.

13. The APR rightly notes that while there was progress in 2005 in terms of road rehabilitation relative to $\mathbf{2 0 0 4}$, the results fell short of expectations, due in part to institutional problems within the Ministry of Transport. The management of the roads program has been streamlined and the institutional restructuring plan is being implemented. The container terminal of the main port of Toamasina, which handles more that 80 percent of the total traffic, has been placed under a concession. But several challenges remain, and the most critical priorities include: (i) resolving the significant accumulation of arrears by the government to companies for VAT refunds and contractual payments, and (ii) ensuring the maintenance of the overall roads program, through the Road Maintenance Fund, in the short and medium term. This problem is particularly acute for rural roads, and the staffs are encouraging the introduction of innovative performance-based contracts for rural road maintenance.

\section{The APR places appropriate emphasis on the financial and structural problems} facing the public utility company (JIRAMA). Economic growth in 2005 was lower owing to production shortfalls linked to power cuts and a loss of competitiveness. However, reforms advanced in 2005 with donor assistance, and in April, a two-year management contract commenced for JIRAMA. A restructuring plan was prepared and presented to donors in Paris in January 2006 and is currently being implemented. Moving forward, the key priorities include steady implementation of the restructuring plan, and implementing the proposal to continue the public-private partnership for JIRAMA through a concession after the two-year management contract expires in April 2007. 
15. The APR notes progress on the environment agenda, including notably the creation of an additional one million hectares of protected areas in $\mathbf{2 0 0 5}$. Staffs believe that the authorities should place priority on assuring that: (i) 8 percent of the MDRI debt relief is allocated to financing the protected areas system; (ii) the concession policy for private management of facilities around protected areas is adopted and implemented; and (iii) the problem of illegal logging is contained and a transparent system of forest licensing is adopted.

16. The APR notes the progress on increasing agricultural productivity, in particular for rice. Moving forward, the key priorities include (i) implementation of the new fertilizer policy; (ii) privatization of seed distribution facilities; and (iii) continued promotion of transformation and diversification of agricultural products.

\section{E. Education}

\section{In line with donors' endorsement of the National Education for All (EFA) plan,} the staffs agree with the strategy outlined in the APR in education and with actions to meet the goals. The government updated its EFA plan in April 2005 and Madagascar received additional funds from the FTI Catalytic funds of US\$10 million for 2005, and US\$25 million each for 2006 and 2007 to support its implementation. The additional funds implement actions to increase salaries for community teachers and to provide competitive school grants to directly facilitate changes at the school level.

18. The overall strategy needs to pay greater attention to improving the quality of the educational system. The government's program resulted in a very significant increase in primary net enrollment rates (from about 67 percent in 2001/02 to about 98 percent in $2004 / 05$, which exceeded expectations) ${ }^{2}$ and in the primary completion rate from about 30 percent to 60 percent over the same period. High repetition and drop out rates remain a concern. In the medium term, the EFA priorities include: (i) implementation of the reform extending the length of primary education from 5 to 7 years; (ii) addressing quality constraints including teacher training and teaching/learning process and curriculum; (iii) improving the school construction program management; and (iv) rationalizing human resources management. Donors are providing technical assistance to the Ministry of Education and Scientific Research (MENRS) for the implementation of the above mentioned actions. At the same time, the government is preparing a strategy on the overall reform of post-primary education.

\footnotetext{
${ }^{2}$ The 2004 Household surveys (EPMs) showed an increase of 14 points of the NER for the same period; from 72 percent in 2002/2003 to 86 percent in 2004/2005. Differences between both sources are noted because MENRS' calculations are based on projections from the 1993 population census, while EPMs figures are from direct calculation from household data. Nonetheless, the significant increase of the NER during the period is valid.
} 


\section{F. Health}

19. As noted in the APR, immunization rates have increased (from 62 percent in 2002 to 87 percent in 2005), child mortality has declined, and the prevalence of HIV/AIDS has remained stable, but progress has stalled in other areas. The percentage of women giving birth in health centers and the consultation rate at health centers has declined and the APR provides rationales for the trend. As recommended in the previous JSA, the government has updated its national health policy and estimated the costs of attaining the health MDGs. Looking forward, the MAP could focus on: (i) finalizing the operationalization of the national health policy by proposing concrete measures, including prioritizing and sequencing of reforms; and (ii) aligning the costing exercise with the resources available in the MAP for the health sector.

\section{G. Nutrition}

20. The National Nutrition Office (ONN), the secretariat for implementing the nutritional policy, is operational. The APR rightly notes the delays in the availability of budget allocations for the program, which have disrupted the implementation and caused the results to fall short of expectations (e.g. the school nutrition program and the number of children in growth promotion program). Moving forward, it is critical to ensure that the institutional arrangements are completed based on the planned institutional assessment, that the budget flows are predictable, and that the scope of the nutrition program is in line with the available resources to maintain quality of service.

\section{H. Rural Water and Sanitation}

21. The overall implementation of the national water supply and sanitation program continues satisfactorily, and the recommendations of the previous JSA have been acted upon. Access to potable water in rural areas has increased from 13 percent to 16 percent between 2003 and 2005. In 2005, an additional 245,000 persons living in rural areas gained access to potable water against 220,500 in 2004. Still, 10 million people in rural areas have no improved access to potable water. Improved access was achieved by the preparation of a 3-year rolling Medium Term Economic Framework, the preparation of a "water and sanitation for all" strategy, including the costs to attain the MDGs, and the establishment of a computerized database for improved monitoring and evaluation. The Directorate of Water and Sanitation of the Ministry of Mines and Energy continues to lead the work on the sector wide approach (SWAP), in close collaboration with key partners. Through improved planning, increased responsibility for service delivery at deconcentrated and decentralized levels, and increased public expenditure accountability and efficiency, the sector has increased its potential absorptive capacity. However, while the total budget for the 
DEA/MEM has increased over the past few years, it still remains insufficient to attain the MDGs.

\section{Monitoring Implementation OF The Poverty Reduction Strategy}

22. The APR elaborates well the monitoring system for the PRSP, the improvements made, and the challenges encountered. As recommended in the previous JSA, the government is clarifying the institutional structure for monitoring the implementation, in particular through efforts in the development of a harmonized planning, monitoring and evaluation system. The ongoing efforts of the government, as elaborated in the APR, for the finalization of institutional arrangements, the harmonization of procedures, methods and tools, as well as the elaboration and implementation of the National Strategy for the Development of Statistics, will be critical to the effective planning, monitoring and evaluation of the implementation of the MAP.

23. The APR describes the participatory process for monitoring the PRSP, including the thematic and regional workshops. However, the APR could have elaborated on the participatory process (notably within the government, involvement of other stakeholders, and mechanisms used to consult the poor and their representatives) and summarized the major issues raised during the process. The systematic participatory process that the government is currently undertaking to develop the MAP is also welcome and will be an important factor for its success.

\section{Conclusions}

24. The APR shows that Madagascar has made good progress in implementing its poverty reduction strategy. In the future, as the government formulates its MAP, the key priorities should include:

(i) identification of the key structural and binding constraints to shared growth, including impediments to domestic private sector activities and further trade liberalization;

(ii) preparation of alternative macroeconomic scenarios within a realistic medium-term framework consistent with the sources of growth analysis, including, notably, the scaling up scenario embedded in the MAP;

(iii) increased mobilization of domestic revenue and improvements in public financial management;

(iv) inclusion of a policy reform matrix which outlines the sequencing and prioritization of the key policy and institutional reforms needed to achieve the MAP's objectives; and (v) adoption of a harmonized system for planning, monitoring and evaluation by all actors, as well as the implementation of the national strategy for the development of statistics to promote greater focus on results. 